\title{
ALIMENTAÇÃO ESCOLAR SAUDÁVEL: UM APORTE AO DESENVOLVIMENTO DO SUJEITO NO/DO CAMPO
}

\author{
Manuela de Jesus Pereira ${ }^{1}$ \\ Rosângela Pereira da Cruz de Araújo²
}

\begin{abstract}
Resumo
Falar em Alimentação do escolar no/do campo, supostamente falamos em educação, direitos, deveres, respeito, autonomia, cidadania, formação integral e nutricional dos sujeitos campesinos em desenvolvimento e humanização, do "SER HUMANO" que traz em toda sua trajetória as marcas do descaso e exclusão do sujeito, que tem suas peculiaridade e especificidades correspondente a sua história de vida. Sua atuação dentro de uma sociedade seletiva e não inclusiva, em que se atua, na busca de respeito e valorização cidadã, de quem trabalha, estuda, e exerce com civismo seu papel sócio histórico político e cultural referente ao povo rural. $O$ trabalho foi realizado através de um estudo bibliográfico, através da leitura, análise e reflexão de vários autores e módulos do PNAE/FNDE embasando assim, esse artigo. Conclui-se que o Programa é de extrema importância para crianças, adolescentes, jovens e adultos em idade escolar uma vez que objetiva amenizar, suprir ou sanar déficit e carência alimentar que consequentemente interferem no intelectivo do sujeito/aluno em desenvolvimento ou na fase intermediária e adulta. Contudo, percebe-se que ainda encontram-se alguns destes sujeitos com desnutrição, carência e deficiência de algumas vitaminas no organismo, então o programa e a alimentação escolar vêm contribuindo assim, com o equilíbrio, desenvolvimento e crescimento dos sujeitos do/no campo.
\end{abstract}

Palavras-Chave: Alimentação Escolar. Educação. Sujeito no/do campo. PNAE.

\begin{abstract}
Speaking of School feeding in / from the field, we are supposed to talk about education, rights, duties, respect, autonomy, citizenship, integral and nutritional training of peasant subjects in development and humanization, of the "HUMAN BEING" that brings in all its trajectory the marks of the subject's neglect and exclusion, which has its peculiarities and specificities corresponding to its life history. Its performance within a selective and non-inclusive society, in which it operates, in the search for respect and citizen appreciation, of those who work, study, and exercise their civic, political and cultural role with respect to the rural people. The work was carried out through a bibliographic study, through the reading, analysis and reflection of several authors and modules of the PNAE / FNDE, thus supporting this article. It is concluded that the Program is extremely important for children, adolescents, young people and school-age adults since it aims to alleviate, supply or remedy deficits and food shortages that consequently interfere in the intellectual of the subject / student in development or in the intermediate and adult. However, it is clear that some of these subjects are still malnourished, lacking

${ }^{1}$ Mestre em Ciências da Educação pela Faculdade Interamericana de Ciências Sociais - FICS. Especialista em GESTÃO ESCOLAR E COORDENACÃO PEDAGÓGICA pela FAC, Especialista em ADMINISTRAÇÃO ESCOLAR E ORIENTAÇÃO EDUCACIONAL pela Dom Alberto e Graduada em Pedagogia pela FAZAG. Docente na Rede Municipal de Cairu- BA, Coordenadora Pedagógica e de Modalidade da Rede Municipal de Madre de Deus-BA, Coordenadora Pedagógica da Rede Municipal de São Francisco do Conde- BA. Email: manuelamorro4@gmail.com.br

2 Doutoranda em Ciências da Educação pela Facultad Interamericana de Ciencias Sociales (FICS). Mestre em Ciências da Educação pela Facultad Interamericana de Ciencias Sociales (FICS). Pósgraduada em: Gestão Escolar com Ênfase em Coordenação Pedagógica (2007) pela Academia de Educação Montenegro; Educação Ambiental pela Universidade Federal da Bahia (2010); Educação de Jovens e Adultos pela Fundação Visconde de Cairu (2014). Possui graduação em Licenciatura Plena em Pedagogia pela Universidade Estadual de Feira de Santana (2006). Atualmente é Coordenadora Pedagógica da Prefeitura Municipal de São Francisco do Conde - BA e Professora da Prefeitura Municipal de Candeias - BA. Email: zanecaraujo@gmail.com
\end{abstract}


and deficient in some vitamins in the body, so the program and school meals have thus contributed to the balance, development and growth of the subjects in the field.

Keywords: School feeding. Education. Subject in / from the field. PNAE.

\section{Introdução}

O presente trabalho versa sobre a importância da alimentação saudável como aporte no desenvolvimento do sujeito do/no campo. Conforme o art. 208, inc. VII da Constituição Federal de 1988 assegura o direito à alimentação escolar a todos os alunos do ensino fundamental por meio de programas de alimentação escolar sendo que a transferência de recursos para manter esses programas seria executada de forma suplementar ao Distrito Federal, estados e municípios que deveriam ter subsídios para a aquisição de gêneros alimentícios possibilitando o fornecimento da merenda aos estudantes, que Teixeira (2008, p. 11) corrobora quando diz, existem várias formas de se abordar a alimentação na escola e uma delas é a merenda escolar.

De acordo com os estudos realizados sobre a saúde, estudantes brasileiros das escolas públicas e do mundo em geral, a Organização Mundial da Saúde (OMS) constatou ser a obesidade um fator preocupante que acomete crianças, adolescentes, jovens e adultos no momento atual.

Sabe-se que outras comorbidades ${ }^{3}$ manifestam-se como hipertensão, diabetes, anemias falciformes, colesterol, triglicérides, carência de ferro e demais nutrientes e vitaminas essenciais ao bom desenvolvimento humano, do sujeito urbano do/no campo nas diversas fases da vida, o que vem a comprometer seu desempenho e relações nas variadas, áreas do conhecimento, do trabalho, do lazer, bem como afetando alguns órgãos e suas funcionalidades.

Salientamos que a oferta de alimentos saudáveis, possibilita aos educandos fazer uso de uma alimentação balanceada o que contribuem para o desenvolvimento psico socioemocional dos sujeitos escolar e favorecem as boas relações, a interatividade com todos e o meio, a cognição/ intelecto, o raciocínio lógico, consequentemente a aprendizagem, através da alimentação sustentável e dos bons hábitos alimentares no cotidiano escolar e sua transferência ao contexto familiar e social, extrapolando assim, os muros escolares.

\footnotetext{
${ }^{3}$ Ocorrem quando há associação entre duas ou mais doenças, ao mesmo tempo, em um
} paciente. 
Diante do exposto, observa-se como de vital importância a inserção dos Programas de Merenda Escolar nas redes estaduais, municipais e distritais de ensino. O mesmo vem subsidiando qualitativamente no que tange a oferta de alimentos saudável, bem como, desenvolvendo e assegurando bons hábitos alimentares e a conscientização dos efeitos benéficos que nos traz para saùde $e$ todo o seu processo existencial, ressaltando que esse trabalho conscientizador deve ser praticado desde o ventre, a partir do que se alimenta a gestante neste período de gestação, perpassando, pelo neonatal, e as fases de criança, adolescentes, jovens e adultos com a oferta de alimentos orgânicos, saudáveis para assim manter uma alimentação equilibrada.

Salienta-se que os atores envolvidos no contexto escolar através de seus responsáveis devem apresentar documentos expedido por um médico especialista atestando ser portador de alguma restrição alimentar, intolerância ou processo alérgico, agitação, síndromes, assim como as demais citadas anteriormente, que precisam de acompanhamento e alimentação diferenciada. Sendo que esse relatório médico fará parte da vida escolar do aluno, sendo anexado à pasta do aluno e uma xerox encaminhada a nutricionista no setor da merenda escolar (SEMAE). Portanto, o nosso objeto de estudo deste artigo é a Alimentação Escolar Saudável: Um subsídio ao sujeito rural no/do campo.

A alimentação oferecida através do Programa de Alimentação Escolar (PNAE), que se instituiu na década de 40 por meio do Governo Federal implementando ações visando ajustar e equalizar as carências nutricionais da refeição realizada no seu contexto familiar. O PNAE e outros programas alimentares tem a finalidade de possibilitar e incentivar bons hábitos alimentares, inibindo, assim, o alto índice de evasão escolar e o déficit de aprendizagem dos atores no contexto escolar público.

\section{Sujeitos da Alimentação Escolar}

Os cidadãos em evidência no contexto brasileiro e de cunho educativo são sujeitos que vivem e se educam no e para o campo, tendo suas especificidades, características oriundas do histórico, político, sócio cultural, na qual se insere objetivos, projetos de vida, sonhos advindos e relacionados diretamente a educação 
cidadã, a terra e a seus produtos agropecuários, no trato relacional com a natureza, que fazem parte do seu cotidiano.

A alimentação oferecida através do PNAE tem como função oferecer alimento em quantidade e qualidade nutricional adequada aos educandos das escolas públicas do campo, visando atender as necessidades dos campesinos durante todo o período em que estiver na escola, contribuindo também com os bons hábitos nutricionais, como também boas práticas alimentares ao longo da vida.

A própria Constituição Federal de 1988 afirma em seu art. 208, inciso VII, que a alimentação escolar é dever do Estado e um direito do educando que frequenta a educação básica e, no art. 6ํㅜ, que a alimentação é um direito social. Sendo assim, um direito dos aprendentes, bem como é dever do Estado manter e efetivar esse direito constitucional adquirido e mediado pelo PNAE, e sendo coordenado pelo FNDE.

Os atores da alimentação escolar para adquirir no ambiente escolar uma alimentação saudável seriam imprescindíveis ações norteadoras e integralizadas que envolva vários sujeitos do processo campesino, que possa assegurar.

O fornecimento de um alimento seguro aos escolares; A formação de um ambiente propício para escolhas alimentares saudáveis; A promoção da educação alimentar e nutricional para toda comunidade escolar.

O nutricionista, responsável técnico pelo PNAE, destaca-se por contribuir com o fortalecimento e disseminação das ações e ideias sobre a alimentação saudável na escola, por meio da interação com a equipe escolar.

Os sujeitos da alimentação do escolar são estes sujeitos do campo, assim como a educação, podemos identificá-los pelo próprio espaço geográfico, pelos dados estatísticos que nos chegam, onde é habitado por um povo brasileiro, suas relações sociais e com a terra que formam a vida do/ no campo de diferentes identidades em comum as pessoas, famílias, movimentos sociais, comunidades e organizações, num propósito de formar, educar sujeitos do campo que reivindicam, se assumam organizadamente sendo protagonistas do seu futuro. Sendo estes na sua integralidade autônomos, politizados e críticos para que saiba se posicionar diante das barreiras impostas, com criticidade e cidadania emancipatória diante de todo processo de persistência e sobrevivência do sujeito campesino ruralista.

\section{A Função do Nutricionista}


O nutricionista é um profissional de saúde de extrema importância, no que se refere a alimentação nutricional escolar, pois foi preparado e capacitado para atuar na prevenção, promoção e recuperação da saúde humana, planejando, executando e avaliando ações baseadas nos conhecimentos da ciências da nutrição e alimentação.

Ele é o responsável técnico do PNAE, auxilia no desenvolvimento das ações fortalecendo as ideias sobre uma alimentação equilibrada e saudável na escola e famílias ligadas diretamente aos alunos na escola, equipe gestora e escolar e a interação com os mesmos durante todo processo educativo anual.

No PNAE este profissional se destaca ao exercer diversas funções como elaborar o cardápio dentro da educação alimentar e nutricional, o do controle de qualidade, integração da agricultura alimentar, teste de aceitabilidade e diagnóstico nutricional.

Cabe a este profissional direcionar uso e manuseio de ferramentas para boa ventilação e conservação dos produtos e sua refrigeração adequada para que não haja perda dos hortifrutigranjeiros e os demais laticínios inseridos na alimentação dos escolares. O nutricionista é o profissional responsável pela elaboração e disseminação do desenvolvimento de bons hábitos alimentares através de reuniões com familiares das crianças, realização de oficinas com a comunidade local e escolar, bem como, os aprendentes do campo.

Em caso de intolerância alimentar e ou qualquer síndrome, autismo, etc, estes alunos terão indicativos de acompanhamento com uma equipe multi/trans e interdisciplinar para que através das terapias os sujeitos campesinos possam se desenvolver e alimentar-se conforme lhes é garantido pelo direito constitucional.

> Planejar, elaborar e acompanhar o cardápio da alimentação dos escolares, levando em consideração as faixas etárias atendidas, suas necessidades, a cultura, costumes alimentar e ainda, compor as refeições com os produtos da terra, da agricultura familiar de pequenos agricultores do campo/rurais;

> Realizar ações e atividades de educação alimentar e nutricional para toda a comunidade escolar, com o apoio da coordenação da escola no planejamento das atividades, que abordem temas relacionados à alimentação saudável e ainda, à consciência ecológica e ambiental; 
$>\mathrm{O}$ nutricionista tem como responsabilidade planejar, coordenar $\mathrm{e}$ supervisionar a aplicação de testes de aceitabilidade com as crianças para a variação de cardápio e inclusão de novos preparos alimentar;

> Realizar o diagnóstico do estado nutricional de cada faixa etária atendida, visando melhor atendimento de suas carências e necessidades;

$>$ Papel fundamental no processo de compra de gêneros alimentícios, através de chamadas públicas e licitações, dando prioridade para a compra direta de gêneros da agricultura familiar;

$>$ Supervisionar e orientar procedimentos realizados na cozinha, como transporte, recebimento, estocagem de alimentos, manipulação adequada e segura no pré-preparo e preparo das refeições, e ainda, elaboração e implantação de manual de Boas Práticas para Serviços de Alimentação.

\section{Armazenamento e Cuidados Com os Alimentos}

Os alimentos perecíveis, semi perecíveis e não perecíveis. Perecíveis são todos os alimentos que estragam com muita facilidade e, por esse motivo, devem ser guardados na geladeira ou no freezer, como: Peixes, carnes, leites e seus derivados, verduras, legumes e algumas frutas, sucos naturais, entre outros.

Semi perecíveis são os alimentos que não estragam com tanta facilidade, como os perecíveis e que não precisam ser guardados na geladeira, como algumas frutas e legumes. Não perecíveis são os alimentos que podem ser armazenados fora da geladeira e do freezer por um determinado tempo. Precisam sempre ser armazenados em lugares secos e ventilados, como feijão, arroz, farinhas, macarrão, etc. Caso esteja deteriorado, realiza-se a troca por outro de boa qualidade.

No caso do fornecedor negar-se a não realizar a troca, caracteriza-se 0 descumprimento do contrato, com sujeição a multas e a outras penalidades cabíveis. Para concluir, é fundamental manter cuidados de armazenagem para a qualidade da alimentação no PNAE: A armazenagem e cuidados no preparo dos alimentos após o recebimento dos alimentos, é fundamental observar as condições de armazenamento, que pode ser realizada tanto no depósito central da EEx como nas escolas.

Para garantir a segurança e a qualidade dos alimentos, deverão ser observadas as seguintes recomendações: Os gêneros alimentícios devem ser 
armazenados separadamente dos produtos de limpeza, pertences pessoais e materiais em desuso. O local deve ser seco, limpo e ventilado.

Somente em 1979 foi dada ao Programa a denominação de Programa Nacional de Alimentação Escolar (PNAE). Apesar de o PNAE aumentar a cada ano a sua cobertura, o aspecto assistencialista do Programa perdurou até a promulgação da Constituição Federal em 1988, que assegurou o direito à alimentação escolar a todos os alunos do ensino fundamental público. Posteriormente, a Emenda Constitucional no 59 de 2009, ampliou a abrangência do atendimento dos programas sociais para toda a educação básica.

Nesse contexto, a Constituição, em seu art. 208, incisos IV e VII, definiu que é dever do Estado (União, estados, Distrito Federal e municípios) a garantia de: Em suma, a Constituição reconheceu o direito do estudante à alimentação escolar, obrigando, inclusive, os estados, o Distrito Federal e os municípios a oferecerem programas suplementares de alimentação aos alunos da educação básica (creche, pré-escola, ensino fundamental, médio e EJA). "Inciso IV: educação infantil, em creche e pré-escolar, às crianças até 05 (cinco) anos de idade. Inciso VII: atendimento ao educando em todas as etapas da educação básica, por meio de programas suplementares de material didático-escolar, transporte, alimentação e assistência à saúde.

Contudo, a escola demanda de uma importante função neste contexto no que se refere manter um bom relacionamento e diálogo com os familiares dos educandos, bem como, com a comunidade local mantendo-os atualizados sobre as boas práticas e bons hábitos alimentares, visando assim a promoção da saúde.

Outra ação importante é de inserir no Projeto Político Pedagógico (PPP) da unidade escolar a temática Alimentação Saudável/sustentável e equilibrada permeando assim, a interdisciplinaridade perpassando pelas demais áreas do conhecimento / componentes curriculares, promovendo o envolvimento de todos e participação, nas reuniões, oficinas e formação continuada dos profissionais da escola.

\section{A Função da Merendeira}

A Merendeira desempenha uma função de suma importância em relação à manipulação, preparação, higienização e manuseio dos alimentos e vasilhames de 
forma responsável e segura, mantendo a qualidade da alimentação dos sujeitos campesinos escolares.

A merendeira tem papel importante na relação com os aprendentes, possibilitando o desenvolvimento dos bons hábitos alimentares, e de higienização pessoal, local, das panelas, vasilhames, assim como, manter os alimentos bem refrigerados e armazenados em temperatura adequada.

Vale ressaltar que os professores e coordenadores são responsáveis por disseminar o conhecimento em sala de aula propondo e articulando atividades pedagógicas que favoreçam garantir bons hábitos alimentares/alimentação saudável. Sendo assim, ambos devem fortalecer suas ações corroborando para o sucesso das ações trabalhadas no contexto escolar com os sujeitos de direito à alimentação escolar, e que estes aprendentes tornem-se disseminadores, formadores e conscientizadores de novos adeptos da alimentação saudável, em qualquer contexto em que se encontre inserido.

A alimentação escolar do Campo deixa dúvida quanto a sua eficácia anterior e atual no sentido local, glocal e global no que se refere aos seus valores de origem cultural. Mesmo existindo alguns indícios de segregação, outros pleiteiam direitos sociais emancipatórios rompendo com paradigmas pré existentes nos espaços públicos e de direito do cidadão.

A alimentação (Merenda) escolar oferecida pelo Programa de Alimentação Escolar (PNAE) designa quantas refeições são oferecidas a cada turno ou em tempo integral nas escolas públicas, sendo contemplado o ensino básico.

O ato de realizar as refeições no espaço escolar está correlacionado a outros saberes que fazem parte do processo de formação psicossocial do educando e ações de Educação Alimentar e nutricional a estudantes de todas as etapas da Educação Básica Pública, sendo que a Creches $R \$ 1,07$. Pré-escola recebe por aluno $R \$$ 0,53.Escolas indígenas e Quilombolas: $R \$ 0,64$,Ensino Fundamental e Médio: $R \$ 0,36$, Educação de Jovens e Adultos $R \$ 0,32$. Ensino Integral $R \$ 1,07$. Programa de fomento às Escolas de Ensino Médio em Tempo Integral R\$2,00. Alunos que frequentam o Atendimento Educacional Especializado no contraturno: $R \$$ 0,53. O repasse é feito diretamente aos estados e municípios, com base no censo escolar realizado no ano anterior ao atendimento.

O Programa é acompanhado e fiscalizado diretamente pela sociedade, por meio dos Conselhos de Alimentação Escolar (CAE), pelo FNDE, e pelo Tribunal de 
Contas da União (TCU), pela Controladoria Geral da União (CGU) e pelo Ministério Público. O PNAE tem por finalidade desenvolver bons hábitos alimentares, comportamental, frequência e de cognição. Com a Lei no 11.947, de 16/6/2009/ 30\% do valor repassado pelo Programa Nacional de Alimentação Escolar- PNAE deve ser investido na compra direta de produtos da Agricultura Familiar, medida que estimula o desenvolvimento econômico e sustentável das comunidades.

O programa atende os alunos de toda a educação básica (Educação Infantil, Ensino Fundamental, Ensino Médio e Educação de Jovens e Adultos) matriculados em escolas públicas, filantrópicas e em entidades comunitárias (conveniadas com o poder público). Vale destacar que o orçamento do PNAE beneficia milhões de estudantes brasileiros, como prevê o artigo 208, inciso IV e VII, da Constituição Federal.

A unidade escolar beneficiária precisa estar cadastrada no Censo Escolar realizado pelo Instituto Nacional de Estudos e Pesquisas Educacionais Anísio Teixeira (INEP/MEC). As escolas filantrópicas, comunitárias e confessionais, sem fins lucrativos, que atendam aos critérios estabelecidos na Resolução FNDE ํㅡㅁ 26/2013, são consideradas integrantes da rede pública de ensino. portanto é de suma importância que o CARDÁPIO ESCOLAR seja elaborado por um profissional (Nutricionista), respeitando os hábitos alimentares locais e culturais da clientela a ser atendida, considerando as necessidades nutricionais específicas, conforme percentuais mínimos estabelecidos no artigo 14 da Resolução nํ26/2013.

A alimentação escolar baseada em alguns princípios e ações para ofertar refeições saudáveis e garantindo a cultura regional em que se encontra o espaço físico e humano sendo originário do trabalho, plantio e colheita, ou seja, da agricultura familiar de onde provém sua subsistência rentável de muitas famílias e alunados diante de ações educacional referente a qualidade nutricional e saudável e acompanhada pelos órgãos que abrange as três esferas federal, estadual e municipal competentes a fiscalizar bem como a sociedade civil na política do PNAE. Mesmo com os avanços jurídicos normativos não foram suficientemente eficazes no seu pleno exercício do direito legal na sociedade e espaços escolares.

Vale ressaltar que a fiscalização e aplicabilidade da verba em favor do bem servir aos alunos deve ser constante e a realização das denúncias é essencial por parte dos conselheiros, pais de alunos, sociedade civil, associação de bairro e funcionários conscientes do seu papel, pois além da merenda escolar, da 
fiscalização, da qualidade nutricional, de um cardápio e quantidade de refeição servida é preciso a instituição escolar juntamente com a família repassar ao órgão competente informações cruciais sobre a saúde e ou comorbidades que alguma criança (aluno) tenha, acompanhado de relatório sobre a restrição de alguns alimentos prejudicial à saúde.

Para tanto uma reunião deverá ser realizada com a equipe escolar, de saúde, pais e ou responsável, bem como a nutricionista do município responsável pelo cardápio a ser servido durante a semana, para substituição necessária a cada enfermidade comprovada com relatório médico pelo especialista e com o Código Internacional de Doenças (CID), e a assinatura, do médico e órgão expedidor Conselho Regional de Medicina Brasileiro (CREMEB).

A alimentação saudável é primordial para crianças em idade escolar, pois é capaz de evitar déficits, carências e excessos nutricionais (CAVALCANTI, 2009). Alimentação escolar de qualidade é um instrumento fundamental para a recuperação de hábitos alimentares saudáveis e, sobretudo, para a promoção tendo caráter suplementar, como prevê o artigo 208, incisos IV e VII, da Constituição Federal, quando afirma que o dever do Estado nas três esferas de governo, com a educação é efetivado mediante a garantia de "atendimento em creche e pré-escola às crianças de zero a seis anos de idade" (inciso IV) (Lei N¹2.061/2009).

Baseando-se nestes acervos documentais e suas leis, o que nos proporcionou embasamento necessário para discorrer o trabalho sobre uma temática de extrema relevância educativa e das Políticas Públicas, no que se refere a direitos educacionais, humanos e da cidadania, de sujeitos que compõem e atuam na sociedade, o que independe de localização e ou espaço geográfico que ocupa (URBANO/CAMPO/RURAL), pois são direitos constitucionais abrangentes a todo cidadão, os quais devem ser efetivados e fiscalizados, assim como, oferecidos respeitando suas especificidades oriundas da regionalidade, de um currículo curricular e componentes que contemplem saberes e fazeres, do histórico sócio cultural identitário de um povo que vive e tece do que a terra lhes oferece como meio de sobrevivência e dignidade, valorizando seus conhecimentos do senso comum e os relacionar ao conhecimento acadêmico dando significância ao ensino aprendizagem.

Cabe aos gestores locais darem a contrapartida cabível no sentido manter e garantir a alimentação ao sujeito do escolar de qualidade e quantidade estipulada 
pelo Programa de alimentação nos turnos e contraturnos que venham atender às carências nutricionais dos campesinos, além de desenvolver bons e saudáveis hábitos alimentares que favorecem uma formação integral do indivíduo.

\section{Considerações}

Diante da temática abordada Alimentação Escolar Saudável no contexto público municipal concluiu-se que os campesinos não vem recebendo uma merenda escolar de qualidade, com valor nutricional adequado. $O$ que valida a má aplicabilidade e efetivação dos recursos públicos recebidos.

Vem sendo notório a carência diante da aparência frágil, baixo desempenho escolar, apatia, que já é decorrente da alimentação familiar e negligência com a qualidade da Alimentação nutricional do escolar(merenda do escolar), oferecida nas unidades escolares. Torna-se recorrente certas situações de carência de vitaminas, nutrientes e minerais encontradas em alguns alimentos como: frutas, verduras, leite e derivados, ovos, carnes, hortaliças. Vale ressaltar que a ingestão de alguns outros alimentos e guloseimas não recomendáveis o uso frequente pode acometer diversos problemas de saúde.

A alimentação inadequada pode levar os sujeitos a desencadear desnutrição, hipertensão, problemas cardiovasculares, renais, diabetes, sobrepeso, obesidade, diminuição do intelecto, entre outros.

O Programa PNAE/FNDE objetiva amenizar, suprir e/ou sanar déficit e carência alimentar que consequentemente interferem no intelecto do sujeito/aluno em desenvolvimento ou na fase intermediária e adulta.

\section{REFERÊNCIAS}

ALMEIDA, S. S. O cotidiano da merenda escolar: análise da experiência em uma escola da Rede Pública Estadual de Ensino do município de Vitória de Santo Antão/PE. Pernambuco. CAV, Saúde Humana e Meio Ambiente, 2014.

ARROYO, G. M; CALDART. S. R; MOLINA. C. M. Por uma Educação do Campo.(Organizadores). Editora Vozes. 5. ed. Petrópolis- RJ. 2011.

BEZERRA, J. A. B. Alimentação e escola: significados e implicações curriculares da merenda escolar. Rev Bras Educ 2009 
BRASIL. Lei no 11.947, de 16 de junho de 2009. Dispõe sobre o atendimento da alimentação escolar e do Programa Dinheiro Direto na Escola aos alunos da educação básica. Brasília: Diário Oficial da União 2009

BRASIL. Ministério da Educação (MEC). Fundo Nacional de Desenvolvimento da Educação. Secretaria de Educação a Distância. 8 ed.Brasília: MEC, FNDE, 2018.

BRASIL. Decreto no 4.582, de 30 de janeiro de 2003. Regulamenta o funcionamento do Conselho Nacional de Segurança Alimentar e Nutricional CONSEA, e dá outras providências. Brasília: Diário Oficial da União 2003

BRASIL. Lei no 11.346, de 15 de setembro de 2006. Cria o Sistema Nacional de Segurança Alimentar e Nutricional - SISAN. Diário Oficial da União 2006

FREITAS, M. C. S, Ramos L, Santos L, Pena P, Santos AC, Ferreira A et al. Direito à alimentação escolar: observações em escolas da Bahia. In: Freitas MCS, AmparoSantos L, Fontes GAV, Ramos L, organizadoras. Narrativas sobre cuidado alimentar e o comer na escola. Salvador: EDUFBA; 2016

GOMES, W. S. T. Alimentação Escolar Saudável. Planaltina - DF: UNB, 2016

KASSAOKA, D; R. MASSARO, M. G. Alimentação escolar: promovendo a saúde do futuro.São Paulo - Coordenadoria de Desenvolvimento dos Agronegócios, 2017.

OLIVEIRA N, Santos S.M.C. Práticas alimentares na escola: um estudo de caso na cidade do Salvador. In: Freitas MCS, Amparo-Santos L, Fontes GAV, Ramos L, organizadoras. Narrativas sobre cuidado alimentar e o comer na escola. Salvador: EDUFBA; 2016.

PAIVA J.B, Freitas M.C.S, Santos L.A.S. Hábitos alimentares regionais no Programa Nacional de Alimentação Escolar: um estudo qualitativo em um município do sertão da Bahia, Brasil. Rev Nutr, 2012

PAIVA J. B, Freitas M.C.S, Santos L.A.S. Significados da alimentação escolar segundo alunos atendidos pelo Programa Nacional de Alimentação Escolar. [s.I]: Ciência Saúde Coletiva 2016

PERRONI, C. Boa alimentação interfere na função cerebral e aumenta a concentração. São Paulo: Saraiva, 2013.

SILVA, E. O. et al. Alimentação escolar e constituição de identidades dos escolares: da merenda para pobres ao direito à alimentação. Cad. Saúde Pública 2018

SOUSA, de C. E. (Organizador). Educação e Ruralidades. Salvador-Bahia: EDUFBA, 2012. 